\title{
Complex treatment of venous leg ulcers including the use of oral nutritional supplementation: results of 12-week prospective study
}

\author{
Paulina Mościcka ${ }^{1,2}$, Justyna Cwajda-Białasik ${ }^{1,2}$, Arkadiusz Jawieńn ${ }^{3}$, Maria T. Szewczyk ${ }^{1,2}$ \\ ${ }^{1}$ Department of Perioperative Nursing, Ludwik Rydygier Collegium Medicum in Bydgoszcz, Nicolaus Copernicus University in Torun, \\ Poland \\ ${ }^{2}$ Outpatient Department for Chronic Wound Management, University Hospital No. 1, Bydgoszcz, Poland \\ ${ }^{3}$ Department of Vascular Surgery and Angiology, Ludwik Rydygier Collegium Medicum in Bydgoszcz, Nicolaus Copernicus University \\ in Torun, Poland
}

Adv Dermatol Allergol 2022; XXXIX (2): 336-346

DOI: https://doi.org/10.5114/ada.2021.104730

\begin{abstract}
Introduction: Malnutrition is known to impair the wound healing process, contributing to wound chronicity. Venous leg ulcers (VLU) represent the most common chronic leg wounds and become epidemiologically relevant in an ageing society.

Aim: This study investigated the effects of a complex treatment, including a specialized oral nutritional supplementation, on the dynamics of the VLU healing.

Material and methods: This 12-week prospective study included 35 individuals with VLU. The patients received professional wound care including specialized dressings. To ensure an optimal nutritional status for wound healing, the patients were asked to drink three times per day $200 \mathrm{ml}$ of an energy-dense protein-rich formula containing arginine, zinc, and vitamins. The healing dynamics were assessed by planimetry.

Results: Complete wound healing was achieved in 6 patients, and the median ulcer area decreased from $26.5 \mathrm{~cm}^{2}$ to $14.8 \mathrm{~cm}^{2}(p=0.0001)$. Both the highest healing rates and most marked increase in prealbumin levels were observed in the first 6-8 weeks. The progress in wound healing was associated with a decreased pain intensity and an improved quality of life. Supplementation was well accepted by the patients.

Conclusions: This study shows that a complex intervention involving nutritional support contributes to a significant progress in VLU healing and promotes the well-being of affected individuals.
\end{abstract}

Key words: wound healing, venous leg ulcer, malnutrition, oral nutritional supplementation, hydrofiber dressing, planimetry.

\section{Introduction}

Wound healing is a complex process which includes many immunological and physiological events [1-4]. Malnutrition is recognized as a major risk factor for wound chronicity [5]. Studies with animal models and clinical trials provided evidence that wound healing demands an optimal state of nutrition, and chronic energy and protein deficiencies markedly suppress the process [1, 2]. Even short-term malnutrition doubles the time of collagen synthesis. Collagen deficiency impairs epithelialization and granulation as well as the remodelling process $[2,6,7]$. On the other hand, increased nutrient requirements dur- ing the healing process, in particular of chronic wounds, can increase metabolic rates, leading to uncontrolled muscle breakdown and severe malnutrition [6]. In a randomized study carried out previously in our centre, we observed that malnutrition and the risk of malnutrition are common among patients with venous ulcers, particularly the elderly. Individuals with ulcers had significantly lower scores of nutritional state, lower body mass index (BMI) values, and lower values of arm and calf circumference when compared with patients without ulcers [8, 9]. According to the European Wound Management Association, the complex care of a patient with a wound should

Address for correspondence: Paulina Mościcka RN, DScN, Department of Surgical Nursing and Chronic Wound Care, Department of Perioperative Nursing, Ludwik Rydygier Collegium Medicum, 1 Łukasiewicza St, 85-821 Bydgoszcz, Poland, phone: +48 525855803 , fax: +48 52 585-58-09, e-mail: p.moscicka@cm.umk.pl Received: 25.01.2021, accepted: 8.02.2021. 
include nutritional screening and, if needed, optimal nutritional support [10].

It is estimated that nutritional support for individuals with wounds should provide an additional daily caloric intake of 30-35 kcal/kg body weight. The extra calories are needed to compensate for the increased anabolism during wound healing. Protein enables proper collagen synthesis, immune function, and fibroblast proliferation, and is essential for all stages of wound healing. In individuals with chronic wounds, a protein provision of up to $1.5 \mathrm{~g} / \mathrm{kg}$ body weight is recommended [4]. Arginine plays an important role in wound healing, not only as a precursor of nitric acid, which regulates inflammation, but also as a substrate for protein synthesis [11, 12]. Among vitamins, $A$ and $C$ are particularly important for wound healing [1]. Vitamin A modulates the immune response during inflammation, exerting anti-inflammatory effects [13], and stimulates fibroblast proliferation [14]. Vitamin C is a cofactor in the process of collagen synthesis and regulates the immune response. From the minerals, zinc, selenium, and iron are beneficial for wound healing as they regulate the immune response, stimulate collagen production, and promote tissue repair and growth [2].

Chronic wounds often affect older or critically ill individuals, who may not be able to fulfil the increased nutritional demands with a regular diet [15]. Therefore, to ensure an optimal nutritional status in these patients, oral nutritional supplementation (ONS) is recommended $[10,16,17]$. Most studies exploring the efficacy of highprotein ONS focused on pressure ulcers. Protein-rich oral formulae containing arginine, zinc, and antioxidants were demonstrated to significantly improve the healing process [18-20].

The role of dietary supplementation in venous ulcer healing is less well documented. Active leg ulcers affect up to $0.6 \%$ of the general population $[21,22]$, and $70-80 \%$ of cases are of venous aetiology $[21,23]$. Venous leg ulcers (VLU) develop because of chronic venous insufficiency. The current management strategy for venous ulcers is based mainly on compression therapy [24, 25], local treatment (debridement and dressings, limb elevation, pain relief, ankle exercises) and improved nutrition $[10,17,24,26-28]$.

Dressings used in the local treatment of VLU should be compatible with compression therapy and effectively absorb exudate under pressure. To minimize the possibility of infection in the VLU, topical treatment must also provide microbiological control (e.g., silver ion dressings and antiseptics).

\section{Aim}

The aim of this preliminary study was to investigate the impact of a 12-week specialized treatment program including supplementation with an energy-dense, high-protein Cubitan formula on the dynamics of venous wound healing.

\section{Material and methods}

This prospective, 12 -week study included 35 adult ( $>18$ years) individuals with chronic leg ulcers of venous aetiology. The recruitment took place between 2017 and 2019. One patient withdrew after the control visit in week 2 of the study, hence 34 patients were included in the final analysis. The enrolled patients had wounds with areas between $5 \mathrm{~cm}^{2}$ and $50 \mathrm{~cm}^{2}$, with ankle-brachial index values of 0.9-1.3, lasting longer than 6 weeks. Exclusion criteria included the presence of wounds of mixed or undiagnosed aetiology, any type of artificial nutrition (e.g., feeding tubes), a state of nutrition score $>3$ (according to the $\mathrm{Nu}$ tritional Risk Screening 2002; NRS-2002) [29], a haemoglobin level $<10 \mathrm{~g} / \mathrm{dl}$, and the presence of coexisting chronic diseases or severe or chronic organ failure. In particular, the conditions that excluded patients from the study were uncontrolled diabetes mellitus (glycated haemoglobin level $>7 \%$ ), advanced renal (serum creatinine concentration $>124 \mathrm{mmol}(>1.4 \mathrm{mg} / \mathrm{ml})$ ) or hepatic insufficiency (viral hepatitis B or ( infection), moderate to advanced cardiac failure, chronic obstructive pulmonary disease or peripheral artery disease, current or previous ( $<1$ year since the last chemotherapy or radiotherapy treatment) neoplastic disease, current immunosuppressive therapy, connective tissue disease, sepsis, and osteomyelitis.

\section{Data collection}

Wound bacterial cultures, body mass index (BMI), ankle-brachial index and blood count measurements were performed in all patients at study entrance. All enrolled patients were treated according to current guidelines for wound care $[11,16,17,24,30]$ and compression therapy (class 2) with short-stretch bandages. The type of dressing and frequency of its change were adjusted to the clinical state of the wound. In the inflammatory phase, absorbent dressings were applied, with or without silver ions, depending on the microbiological condition of the wound (e.g., AQUACEL ${ }^{\oplus}$ Foam, AQUACEL ${ }^{\circledR}$ Ag Foam, ConvaTec). In the phases of granulation and epithelialization, the new tissues were protected with hydrocolloid dressings (e.g., Granuflex ${ }^{\circledR}$ or Granuflex Extra Thin ${ }^{\oplus}$, ConvaTec) or mesh contact layers. Each patient attended an outpatient clinic twice a week. In case of infection and local symptoms of infection, antibiotic susceptibility testing was performed, and appropriate targeted antibiotic therapy was administered accordingly.

During the study, each patient received 3 bottles per day $(3 \times 200 \mathrm{ml})$ of an energy-dense, protein-rich oral Cubitan (Nutricia) formula to be consumed throughout the day between meals. Such supplementation provided the patient with $128 \mathrm{kcal}, 10 \mathrm{~g}$ of protein, and $1.5 \mathrm{~g}$ of L-arginine per $100 \mathrm{ml}$ of formula, macro- and micronutrients (e.g., $\mathrm{Na}, \mathrm{K}, \mathrm{Cl}, \mathrm{Ca}, \mathrm{Mg}$, Fe, Zn, Se), and vitamins (e.g., A, $\left.\mathrm{D}, \mathrm{E}, \mathrm{K}, \mathrm{B}_{6}, \mathrm{~B}_{12}, \mathrm{C}\right)$. Treatment compliance was determined based on the number of returned bottle caps (Table 1). 
Table 1. Compliance to oral nutritional supplementation throughout the study

\begin{tabular}{|c|c|c|c|c|}
\hline ONS consumption rate & $\begin{array}{c}1^{\text {st }} \\
\text { month }\end{array}$ & $\begin{array}{c}2^{\text {nd }} \\
\text { month }\end{array}$ & $\begin{array}{c}3^{\text {rd }} \\
\text { month }\end{array}$ & $\begin{array}{l}\text { Whole } \\
\text { study }\end{array}$ \\
\hline ONS intolerance $^{\dagger}$ & 0 & 0 & 0 & 0 \\
\hline $20-59 \%$ weekly dose ${ }^{x}$ & 3 & 1 & 1 & 1 \\
\hline $60-74 \%$ weekly dose ${ }^{x x}$ & 2 & 3 & 1 & 3 \\
\hline $75-100 \%$ weekly dose & 29 & 30 & 32 & 30 \\
\hline
\end{tabular}

ONS - oral nutritional supplementation. ${ }^{\dagger}$ ONS intolerance was defined as consumption of less than $20 \%$ of the recommended ONS dose ( $<120 \mathrm{ml} /$ day) for 5 consecutive days. ${ }^{\times}$Consumption of 20-59\% of the weekly dose in the first week of the study ( $<2520 \mathrm{ml} /$ week, $<13$ returned caps), ${ }^{x x}$ consumption of 60 $74 \%$ of the weekly dose in the consecutive weeks after study inclusion $(<450$ $\mathrm{ml} /$ day, $<3150 \mathrm{ml} /$ week, < 16 returned caps in a week, < 32 returned caps after 2 weeks, < 47 returned caps after 3 weeks, < 63 returned caps after 4 weeks).
The dynamics of wound healing were assessed by planimetry and photographic documentation every two weeks during the 12-week study. The primary endpoint, complete wound healing, was defined as a reduction in the wound area by $100 \%$. The secondary endpoints included the change in the ulcer area (in $\mathrm{cm}^{2}$ and as a percentage change from baseline), the change in the ulcer area assessed for small $\left(<20 \mathrm{~cm}^{2}\right)$ and large $\left(\geq 20 \mathrm{~cm}^{2}\right)$ ulcers (in $\mathrm{cm}^{2}$ and as a percentage change from baseline), and the percentage change (from baseline) in wound bed tissue composition, including epithelial tissue, granulation tissue, fibrin, and sloughy tissue.

The following clinical parameters were also assessed: serum prealbumin levels (at week 0, 6 and 12), pain in-

Table 2. Baseline characteristics of the study group $(n=35)$

\begin{tabular}{|c|c|c|c|c|}
\hline Parameter & Mean (SD) & Median & Range & $95 \% \mathrm{Cl}$ \\
\hline Age [years] & $71.7(11.3)$ & 73.0 & $47.0-96.0$ & $67.8-75.6$ \\
\hline Sex, male ${ }^{\dagger}$ & $13(37 \%)$ & & & \\
\hline Body weight & $85.4(17.2)$ & 85.0 & $55.0-135.0$ & $79.5-91.3$ \\
\hline Height [m] & $1.7(0.1)$ & 1.7 & $1.5-1.9$ & $1.7-1.7$ \\
\hline $\mathrm{BMI}\left[\mathrm{kg} / \mathrm{m}^{2}\right]$ & $30.2(6.5)$ & 30.7 & $20.7-52.7$ & $28.0-32.4$ \\
\hline \multicolumn{5}{|l|}{ BMI category $\left[\mathrm{kg} / \mathrm{m}^{2}\right]:^{+}$} \\
\hline$<18.5$ (underweight) & $1(2.9 \%)$ & & & \\
\hline 18.5-24.99 (normal weight) & $9(25.7 \%)$ & & & \\
\hline 25.0-29.99 (overweight) & $6(17.1 \%)$ & & & \\
\hline 30.0-39.99 (obesity) & $13(37.1 \%)$ & & & \\
\hline$\geq 40.0$ (morbid obesity) & $6(17.1 \%)$ & & & \\
\hline Serum prealbumin level [mg/dl] & $19.9(5.6)$ & 19.0 & $11.0-33.0$ & $17.9-21.8$ \\
\hline \multicolumn{5}{|l|}{ Compression therapy used ${ }^{+}$: } \\
\hline None & $9(25.7 \%)$ & & & \\
\hline Bandages & $1(2.9 \%)$ & & & \\
\hline Kings & 25 (71.4\%) & & & \\
\hline Ulcer duration [months] & $78.8(101.7)$ & 36.0 & $2.0-420.0$ & $43.8-113.7$ \\
\hline \multicolumn{5}{|l|}{ Comorbidities $^{\dagger}$ : } \\
\hline Osteoarthritis & $13(37.1 \%)$ & & & \\
\hline Heart diseases & $9(25.7 \%)$ & & & \\
\hline Rheumatoid arthritis & $7(20.0 \%)$ & & & \\
\hline Diabetes mellitus & $6(17.1 \%)$ & & & \\
\hline Atherosclerosis & $5(14.3 \%)$ & & & \\
\hline Others & $18(51.4 \%)$ & & & \\
\hline \multicolumn{5}{|l|}{ Ulcer characteristics ${ }^{\dagger}:$} \\
\hline Shallow & $30(86 \%)$ & & & \\
\hline Deep: $1^{\text {st }}, 2^{\text {nd }}, 3^{\text {rd }}$ degree & \multicolumn{3}{|c|}{8 (23\%), 21 (60\%), 4 (11\%) } & \\
\hline Single & $11(31 \%)$ & & & \\
\hline Multiple & $24(69 \%)$ & & & \\
\hline
\end{tabular}

†Shown as the number of observations (percentage). SD - standard deviation, $\mathrm{Cl}$-confidence interval of the mean, BMI - body mass index. 

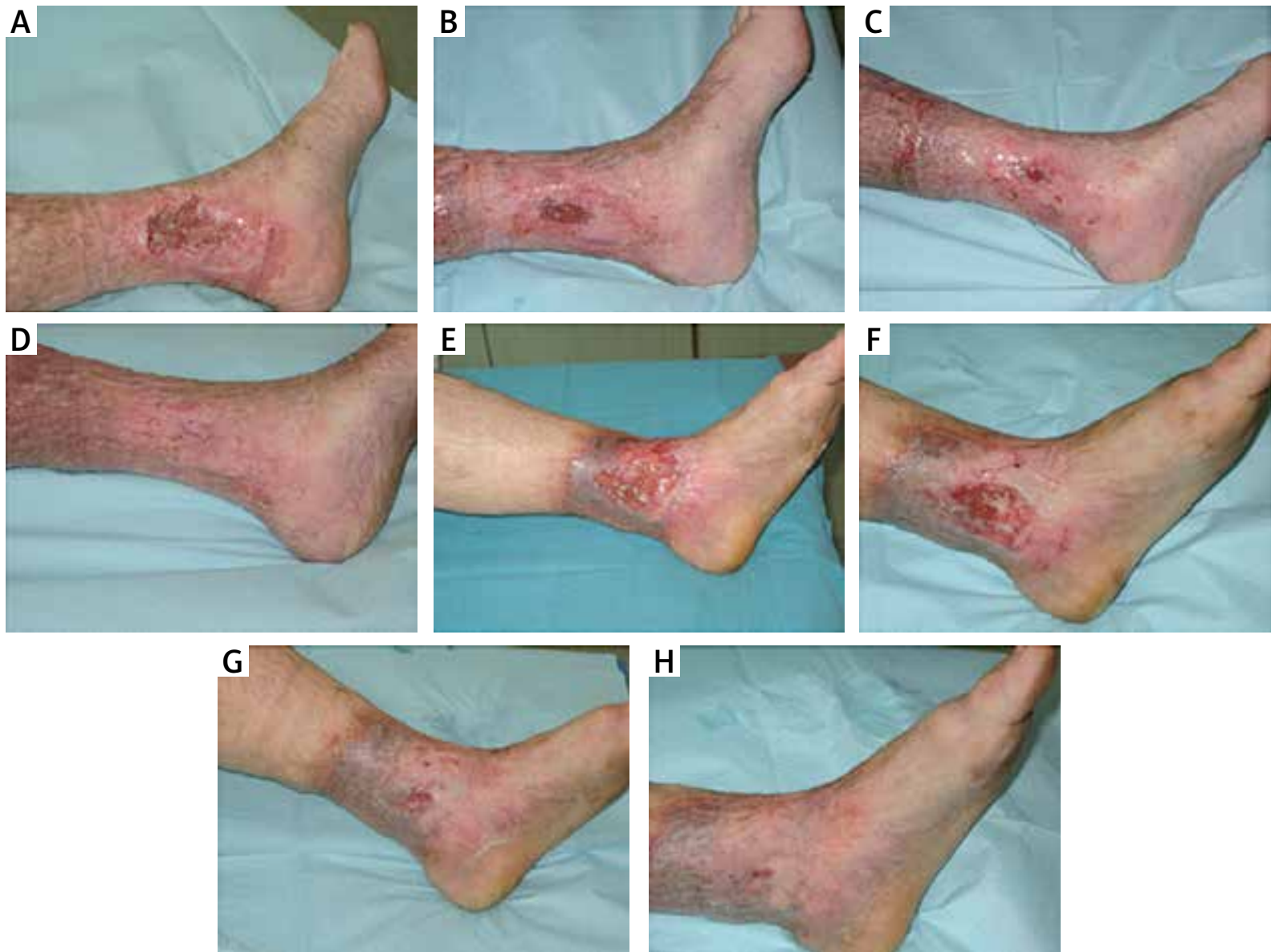

Figure 1. Photographic documentation of venous leg ulcers healing. A-D - patient 1 in week 1, 3, 7, and 9, respectively. $\mathbf{E}-\mathbf{H}$ - patient 2 in week $1,3,5$, and 7, respectively

tensity on a 1 to 10 scale (a maximum value from the current day and an average weekly value). Additionally, a WHOQOL-BREF questionnaire [31] was used for quality of life assessment at week 0 and 12 of the study.

The study protocol was approved by the local bioethical committee (No. KB 467/2016). All enrolled patients gave written informed consent to participate in the study. All experiments were performed in accordance with relevant guidelines and regulations.

\section{Statistical analysis}

All statistical calculations were done with Statistica version 12.0 (StatSoft) and Microsoft Excel software. $P$-values $<0.05$ were considered significant.

\section{Results}

A summary of the baseline characteristics of the patients and their clinical condition is shown in Table 2. Photographs illustrating the healing process are included in Figure 1.
Most patients adhered well to recommendations regarding ONS intake, with consumption exceeding 75\% of the suggested dose declared by 30 out of 34 patients (88\%). Compliance to ONS remained stable throughout the study. Additionally, recorded adverse events were infrequent and transient. In the first week of the treatment, only 3 patients reported signs of ONS intolerance (e.g., diarrhoea, feeling of satiety, decreased appetite, nausea). For these patients, the following suggestions were made: decrease the volume of consumed formula, drink the formula in small portions, and gradually increase daily doses. This led to improved tolerance in the following weeks and thus to a greater number of returned caps in the $2^{\text {nd }}$ and $3^{\text {rd }}$ month of the study (Table 1 ).

\section{Ulcer area changes}

Complete wound healing was achieved by 6 patients $(18 \% ; p=0.033)$ - all from the small ulcer subgroup $(6 / 16,37.5 \% ; p=0.32)$. When ulcer multiplicity was considered, 3 patients with single ulcers $(3 / 10,30 \% ; p=0.21)$ and 3 patients with multiple ulcers $(3 / 24,13 \% ; p=0.001)$ 
experienced complete wound healing. For patients who achieved complete wound healing, the median ulcer duration before study enrolment was 14 months (range: 6-60 months).

During the study, the median ulcer area decreased from $26.5 \mathrm{~cm}^{2}$ to $14.8 \mathrm{~cm}^{2}$. Statistically significant differences in the ulcer area from baseline were observed from week 2 to the end of the study. The percentage change in the initial ulcer area increased from $7.4 \%$ in week 2 to $43.6 \%$ in week 12 , reaching statistical significance in week 8 . A gradual decrease in ulcer size was also observed in subgroup analyses, including ulcer size and ulcer multiplicity (single vs. multiple ulcers), with significant differences from baseline observed from week 8 of the study. Detailed characteristics of changes in the ulcer area are given in Table $3 \mathrm{~A}$.

We monitored changes in the composition of the wound bed to gain a better insight into the dynamics of the healing process (Table $3 \mathrm{~B}$ ). The median content of epithelial and granulation tissue increased systematically. On the other hand, the fibrin content in the wound bed decreased.

\section{Prealbumin levels}

Changes in prealbumin levels throughout the study were not statistically significant. However, during the first 6 weeks of the study, the mean prealbumin levels increased noticeably from $19.9 \mathrm{mg} / \mathrm{dl}$ to $21.6 \mathrm{mg} / \mathrm{dl}$, and remained stable during the last 6 weeks of the study (Table 4).

\section{Changes in chronic venous disorders, pain intensity and quality of life}

A significant decrease in the CEAP-C6 classification [31] score was observed during the study, with median values of 12 (range: 9-16) in week 0, and 10 (range: 0-15) in week 12 (W0 vs. W12; $p=0.0004$ ).

Both patient self-assessments for pain intensity, the maximum value from the day and the average value from the week, constantly decreased from 5 to 2 throughout the study (Table $3 \mathrm{C}$ ). When compared to the baseline assessments for week 0 , a decrease in pain intensity was statistically significant starting from week 6 for the daily assessment and week 7 for the weekly assessment.

The results of the quality of life assessment using the WHOQOL-BREF questionnaire are presented in Table 5. Significant improvements between assessments at study entrance (WO) and at the end of the study (W12) occurred on the general and environment scales. No major changes were observed in the physical, psychological, and social domains.

\section{Discussion}

As a result of increasing life expectancy and population ageing, VLU is becoming a significant economic and epidemiological public health issue. Its prevalence increases with age, affecting as much as $2 \%$ of individuals older than 80 years [32-36]. VLU are caused by venous insufficiency, calf muscle pump failure, and vascular valve incompetence that results in venous hypertension [37]. Therefore, the origin of VLU is distinct from that of pressure [38], neuropathic, or arterial ulcers [37]. VLU are of chronic course, with high recurrence rates of up to $28 \%$ per year [39]. Additionally, they are painful, prone to infection, and may restrict the patient's mobility, and thus drastically deteriorate the quality of life [40, 41]. VLU are associated with severe psychosocial consequences, such as depression and disturbances in sleep and daily living activities [41]. The management of VLU is complex and requires multi-disciplinary care. It involves compression therapy, which reduces venous hypertension by applying external pressure, the use of specialized dressings, pharmacotherapy, and surgical treatment [10, 16]. Additionally, the current VLU management guidelines recommend an assessment of the nutritional state of the patients and adequate application of nutritional support to promote wound healing $[10,16,17,24]$.

Malnutrition affects $5-10 \%$ of older individuals living independently, and up to $65 \%$ and $85 \%$ of those in hospitalized and home nursing populations, respectively (encompasses undernutrition (resulting from insufficient or inadequate food consumption), overnutrition, and deficits in particular nutrients) [14, 42]. A pilot study including nine hospitalized patients with leg ulcers, including VLU, showed that the nutritional status of individuals with chronic wounds is inadequate, and oral food intake is insufficient to cover their energy and protein requirements [15]. Patients with VLU were shown to have protein, vitamin A and E, and zinc deficiencies [43, 44]. Moreover, the intake of proteins, vitamins, and minerals among elderly patients, who are at a high risk of VLU, is insufficient $[45,46]$. On the other hand, the demand for both energy and building substrates greatly increases during the wound healing process [2]. The shortage of endogenous substrates in malnourished patients impairs and delays the healing process by prolonging the inflammatory phase, restricting collagen synthesis, and impeding the immune function [47]. Using ONS, which provides an additional, easy-to-consume source of energy, proteins, essential micronutrients, amino acids, and vitamins, may be therefore beneficial in VLU patients.

Here, we showed that professional wound management in a specialized medical centre, together with energy-dense high-protein oral supplementation, led to a significant clinical improvement in patients suffering from VLU. Moreover, we provided evidence that a relatively short, 3-month treatment allowed for complete wound healing in 6 patients with long-term ( $\geq 1$ year) ulcers (4/6) and very long-term ( $\geq 3$ years) ulcers (2/6). This underlines the high efficacy of such a complex approach that combined professional care in a specialized 
Table 3. Changes in the ulcer area (part A), wound bed composition (part B) and pain intensity (part C) during a 12-week supplementation with Cubitan formula

\begin{tabular}{|c|c|c|c|c|c|c|}
\hline \multirow{2}{*}{$\begin{array}{l}\text { Part A } \\
\text { Week }\end{array}$} & \multicolumn{3}{|c|}{ Ulcer area $\left[\mathrm{cm}^{2}\right]$} & \multicolumn{3}{|c|}{ Percentage change from wo } \\
\hline & Median & Range & $P($ vs. W0)* & Median & Range & $P($ vs. W2)* \\
\hline \multicolumn{7}{|c|}{ Overall analysis $\left(n=35^{\dagger}\right)$ : } \\
\hline wo & 26.5 & $3.3-56.5$ & - & - & - & - \\
\hline W2 & 26.1 & $0.0-60.0$ & $<0.05$ & 7.4 & $-32.3-100.0$ & - \\
\hline W4 & 20.9 & $0.0-48.0$ & $<0.05$ & 17.2 & $-22.2-100.0$ & $>0.05$ \\
\hline W6 & 19.3 & $0.0-48.5$ & $<0.05$ & 19.4 & $-95.8-100.0$ & $>0.05$ \\
\hline W8 & 15.2 & $0.0-45.0$ & $<0.05$ & 26.9 & $-84.2-100.0$ & $<0.05$ \\
\hline W10 & 14.7 & $0.0-40.5$ & $<0.05$ & 34.2 & $-55.8-100.0$ & $<0.05$ \\
\hline W12 & 14.8 & $0.0-39.2$ & $<0.05$ & 43.6 & $-116.8-100.0$ & $<0.05$ \\
\hline \multicolumn{7}{|c|}{ Subgroup analysis: ulcer multiplicity: } \\
\hline \multicolumn{7}{|c|}{ Single ulcers $\left(n=11^{\dagger}\right)$ : } \\
\hline Wo & 5.2 & $3.3-47.5$ & - & - & - & - \\
\hline W2 & 4.6 & $3.7-38.0$ & $>0.05$ & 14.3 & $-32.3-50.0$ & - \\
\hline W4 & 3.9 & $2.1-40.1$ & $>0.05$ & 24.5 & $11.5-65.4$ & $>0.05$ \\
\hline W6 & 3.8 & $2.1-40.8$ & $>0.05$ & 29.1 & $14.1-73.1$ & $>0.05$ \\
\hline W8 & 3.0 & $1.3-39.6$ & $<0.05$ & 37.1 & $16.0-83.3$ & $>0.05$ \\
\hline W10 & 2.6 & $0.3-38.4$ & $<0.05$ & 51.5 & $19.2-96.2$ & $<0.05$ \\
\hline W12 & 2.0 & $0.0-37.9$ & $<0.05$ & 66.2 & $20.2-100.0$ & $<0.05$ \\
\hline \multicolumn{7}{|c|}{ Multiple ulcers $(n=24)$ : } \\
\hline wo & 38.3 & $4.8-56.5$ & - & - & - & - \\
\hline W2 & 33.7 & $0.0-60.0$ & $>0.05$ & 4.0 & $-12.4-100.0$ & - \\
\hline W4 & 28.7 & $0.0-48.0$ & $>0.05$ & 14.5 & $-22.2-100.0$ & $>0.05$ \\
\hline W6 & 31.9 & $0.0-48.5$ & $>0.05$ & 17.9 & $-95.8-100.0$ & $>0.05$ \\
\hline W8 & 29.6 & $0.0-45.0$ & $<0.05$ & 20.8 & $-84.2-100.0$ & $<0.05$ \\
\hline W10 & 27.0 & $0.0-40.5$ & $<0.05$ & 27.6 & $-55.8-100.0$ & $<0.05$ \\
\hline W12 & 25.5 & $0.0-39.2$ & $<0.05$ & 35.1 & $-116.8-100.0$ & $<0.05$ \\
\hline \multicolumn{7}{|c|}{ Subgroup analysis: ulcer size: } \\
\hline \multicolumn{7}{|c|}{ Small $\left(<20 \mathrm{~cm}^{2}\right)$ ulcers $(n=16)$ : } \\
\hline wo & 5.4 & $3.3-17.5$ & - & - & - & - \\
\hline W2 & 4.9 & $0.0-19.1$ & $>0.05$ & 10.4 & $-32.3-100.0$ & - \\
\hline W4 & 4.1 & $0.0-18.5$ & $>0.05$ & 26.7 & $-22.2-100.0$ & $>0.05$ \\
\hline W6 & 3.8 & $0.0-16.9$ & $>0.05$ & 30.8 & $-95.8-100.0$ & $>0.05$ \\
\hline W8 & 3.0 & $0.0-13.5$ & $<0.05$ & 37.1 & $-84.2-100.0$ & $>0.05$ \\
\hline W10 & 2.6 & $0.0-12.3$ & $<0.05$ & 49.5 & $-55.8-100.0$ & $<0.05$ \\
\hline W12 & 2.0 & $0.0-14.6$ & $<0.05$ & 63.4 & $-116.8-100.0$ & $<0.05$ \\
\hline \multicolumn{7}{|c|}{ Large $\left(\geq 20 \mathrm{~cm}^{2}\right)$ ulcers $\left(n=19^{\dagger}\right)$ : } \\
\hline wo & 47.5 & $20.9-56.5$ & - & - & - & - \\
\hline W2 & 41.4 & $18.8-60.0$ & $>0.05$ & 4.0 & $-12.1-36.5$ & - \\
\hline W4 & 36.3 & $18.5-48.0$ & $>0.05$ & 14.6 & $-11.2-51.6$ & $>0.05$ \\
\hline W6 & 37.4 & $17.2-48.5$ & $>0.05$ & 17.8 & $-31.7-55.4$ & $>0.05$ \\
\hline W8 & 35.5 & $15.0-45.0$ & $<0.05$ & 20.4 & $-21.4-68.8$ & $<0.05$ \\
\hline W10 & 33.3 & $10.3-40.5$ & $<0.05$ & 27.9 & $-40.1-64.6$ & $<0.05$ \\
\hline W12 & 30.7 & $6.8-39.2$ & $<0.05$ & 36.5 & $-36.8-68.8$ & $<0.05$ \\
\hline
\end{tabular}


Table 3. Cont.

\begin{tabular}{|c|c|c|c|c|c|c|}
\hline \multirow{2}{*}{$\frac{\text { Part B }}{\text { Week }}$} & \multicolumn{3}{|c|}{ Percentage tissue content } & \multicolumn{3}{|c|}{ Percentage change from wo } \\
\hline & Median & Range & $P($ vs. W0)* & Median & Range & $P(\text { vs. W2 })^{\star *}$ \\
\hline \multicolumn{7}{|c|}{ Epithelial tissue: } \\
\hline Wo & 10.0 & $0-25$ & - & - & - & - \\
\hline W2 & 15.0 & $0-100$ & $>0.05$ & 40.0 & $0-900$ & - \\
\hline W4 & 25.0 & $5-100$ & $<0.05$ & 133.3 & $0-1200$ & $>0.05$ \\
\hline W6 & 35.0 & $5-100$ & $<0.05$ & 200.0 & $0-1600$ & $<0.05$ \\
\hline W8 & 40.0 & $10-100$ & $<0.05$ & 216.7 & $0-1700$ & $<0.05$ \\
\hline W10 & 47.5 & 10-100 & $<0.05$ & 308.3 & $33-1900$ & $<0.05$ \\
\hline W12 & 57.5 & 10-100 & $<0.05$ & 375.0 & $66-1900$ & $<0.05$ \\
\hline \multicolumn{7}{|c|}{ Granulation tissue: } \\
\hline Wo & 15.0 & $5-85$ & - & - & - & - \\
\hline W2 & 40.0 & $0-80$ & $<0.05$ & 120.0 & $-100-900$ & - \\
\hline W4 & 42.5 & $0-60$ & $<0.05$ & 145.0 & $-100-1000$ & $>0.05$ \\
\hline W6 & 40.0 & $0-65$ & $<0.05$ & 100.0 & $-100-1100$ & $>0.05$ \\
\hline W8 & 40.0 & $0-65$ & $<0.05$ & 106.7 & $-100-1200$ & $>0.05$ \\
\hline W10 & 37.5 & $0-80$ & $<0.05$ & 90.0 & $-100-1300$ & $>0.05$ \\
\hline W12 & 30.0 & $0-65$ & $>0.05$ & 73.3 & $-100-900$ & $>0.05$ \\
\hline \multicolumn{7}{|c|}{ Sloughy tissue, fibrin: } \\
\hline wo & 70.0 & $5-95$ & - & - & - & - \\
\hline W2 & 40.0 & $0-85$ & $>0.05$ & 50.0 & $-14.3-100.0$ & - \\
\hline W4 & 25.0 & $0-80$ & $<0.05$ & 65.7 & $-7.1-100.0$ & $>0.05$ \\
\hline W6 & 15.0 & $0-75$ & $<0.05$ & 77.4 & $0.0-100.0$ & $<0.05$ \\
\hline W8 & 10.0 & $0-85$ & $<0.05$ & 83.3 & $5.6-100.0$ & $<0.05$ \\
\hline W10 & 7.5 & $0-65$ & $<0.05$ & 88.9 & $27.8-100.0$ & $<0.05$ \\
\hline W12 & 5.0 & $0-70$ & $<0.05$ & 94.4 & $22.2-100.0$ & $<0.05$ \\
\hline Part C & \multicolumn{3}{|c|}{ Pain - daily maximum ${ }^{\ddagger}$} & \multicolumn{3}{|c|}{ Pain - weekly average ${ }^{\S}$} \\
\hline Week & Median & Range & $P($ vs. W0)* & Median & Range & $P$ (vs. W2) $^{*}$ \\
\hline wo & 5.0 & $1.0-10.0$ & - & 5.0 & $1.0-10.0$ & - \\
\hline W1 & 4.5 & $1.0-10.0$ & $>0.05$ & 4.0 & $1.0-10.0$ & $>0.05$ \\
\hline W2 & 4.0 & $0.0-9.0$ & $>0.05$ & 4.0 & $0.0-9.0$ & $>0.05$ \\
\hline W3 & 3.0 & $0.0-9.0$ & $>0.05$ & 3.0 & $0.0-9.0$ & $>0.05$ \\
\hline W4 & 3.0 & $0.0-8.0$ & $>0.05$ & 3.0 & $0.0-8.0$ & $>0.05$ \\
\hline W5 & 3.0 & $0.0-8.0$ & $<0.05$ & 3.0 & $0.0-8.0$ & $>0.05$ \\
\hline W6 & 3.0 & $0.0-8.0$ & $<0.05$ & 3.0 & $0.0-8.0$ & $<0.05$ \\
\hline W7 & 2.5 & $0.0-6.0$ & $<0.05$ & 3.0 & $0.0-7.0$ & $<0.05$ \\
\hline W8 & 2.0 & $0.0-6.0$ & $<0.05$ & 2.0 & $0.0-7.0$ & $<0.05$ \\
\hline W9 & 2.5 & $0.0-6.0$ & $<0.05$ & 2.0 & $0.0-6.0$ & $<0.05$ \\
\hline W10 & 2.5 & $0.0-6.0$ & $<0.05$ & 2.0 & $0.0-6.0$ & $<0.05$ \\
\hline W11 & 2.0 & $0.0-6.0$ & $<0.05$ & 2.0 & $0.0-6.0$ & $<0.05$ \\
\hline W12 & 2.0 & $0.0-6.0$ & $<0.05$ & 2.0 & $0.0-6.0$ & $<0.05$ \\
\hline
\end{tabular}

${ }^{*}$ Calculated with the Friedman test ( $p=0.0001$ for both absolute change and percentage change analyses) and post-hoc Dunn's test. P-values $<0.05$ are marked in bold. ${ }^{* *}$ Calculated with the Friedman test ( $p=0.0001,0.025,0.0001$ for analyses of epithelial tissue, granulation tissue and sloughy tissue, fibrin, respectively) and post-hoc Dunn's test. P-values $<0.05$ are marked in bold. ${ }^{\dagger}$ One patient with a single large ulcer withdrew from the trial after W2. WO - week 0 (baseline); W2 - week two; etc. ${ }^{\ddagger}$ Maximum value for the day of examination (pain intensity assessed on a 0 to 10 scale). ${ }^{\circledR}$ Average day for the week preceding examination. 
centre, the use of advanced dressings, and nutritional support with energy-dense high-protein ONS enriched with arginine, zinc, and vitamins.

Throughout the study, the dynamics of healing was unequivocal. In 12 weeks, the median ulcer area decreased from $26.5 \mathrm{~cm}^{2}$ to $16.8 \mathrm{~cm}^{2}$, and the decrease was the most pronounced in the first $6-8$ weeks of the study. The same observation was made for the subgroup of patients with small and single ulcers. Interestingly, changes in prealbumin levels throughout the study followed a similar pattern: the highest increase occurred in the first 6 weeks of the study and the levels remained stable in the next 6 weeks. The baseline median serum prealbumin was at the lower limit of the normal range, revealing the presence of protein depletion in the study group and suggesting that malnutrition was common among the patients despite a high BMI. Therefore, supplementation with the high-protein Cubitan (Nutricia, Hoofddorp, the Netherlands) formula may have corrected the nutritional deficit, and thus contribute to the enhanced healing rates observed in the first part of the study. In the group of patients with large and multiple ulcers, the healing progress remained stable during the 12 weeks of the study. This observation agrees with clinical experience that more complicated, larger, and multiple ulcers need longer time to heal [48-50].

The dynamics of the wound healing process throughout the study were observed in the changes in wound bed composition, typical of the healing process. The initial increase in the granulation tissue content, together with the gradual increase in epithelial tissue content, and the associated decrease in sloughy tissue and fibrin indicated progress in the healing process.

Along with the progress in wound healing, we observed an improvement in the patients' condition and well-being. A significant decrease in pain intensity was achieved in week 6 and was in line with the progress in the wound healing process. The quality of life increased markedly at the end of the study when compared to baseline. This confirmed the earlier observations that VLU may negatively impact the patients' well-being and a complex treatment may reverse these effects.

Literature focused on the analysis of oral supplementation in VLU healing is scarce. A recent systematic review describes only three papers that included dietary intervention for VLU management [51]. Two of these studies described the role of a single dietary component supplementation of vitamin D [52] and folic acid [53] on the course of VLU healing. Both interventions improved the healing process when compared to standard treatment, but the effect of vitamin D supplementation was not statistically significant. Another study proved the efficacy of a complex, flavonoid-rich nutraceutical product in VLU management, which contributed to enhanced healing and reduced recurrence rates [54]. There is no clear evidence, however, for the possible impact of an energy-dense protein-rich ONS on VLU healing. Raffoul et al. evaluated the impact of a high-calorie high-protein ONS on the healing process of 9 patients with various leg ulcers, including 3 cases of VLUs and pressure and ischemic ulcers. Complete wound healing was achieved in all cases [15]. A complex, energy-dense ONS with high protein content, enriched with vitamin $C$ and zinc, was applied in six individuals with VLU [55]. At the end of the 9-month intervention, progressive wound healing was observed in most patients. However, because these studies used very small sample sizes, strong conclusions on the role of nutritional support in VLU treatment cannot be drawn. In contrast, the benefits of complex ONS are much better documented in the management of pressure ulcers. Cereda et al. showed that malnourished patients receiving an energy-dense, protein-rich ONS enriched with arginine, zinc, and vitamins, had improved healing parameters compared with those receiving a standard hospital diet or a high-calorie and protein ONS $[18,19]$. Similarly, Desneves et al. demonstrated the benefits of an ONS enriched with arginine, zinc, and vitamin C on pressure ulcer healing compared to an ONS with high calorie and protein content only [56]. This indicates the key role for these nutrients in promoting wound healing. The high efficacy of so-called woundONS in ulcer healing, including arginine, zinc, and vitamin C, has also been described in original research papers [18-20] and review papers [57, 58]. In our study, we used an ONS formula containing arginine, zinc, and vitamins, which has been demonstrated to be highly efficacious.

Overweight and obesity are recognized as independent risk factors for VLU development [59, 60], and excess body mass is associated with delayed VLU healing [48]. In the above-mentioned studies, patients with normal or low body weight prevailed [15, 52-55]. By contrast, most patients recruited in this study had a $\mathrm{BMI}>30 \mathrm{~kg} / \mathrm{m}^{2}$. We observed that patients with a high BMI were still characterized by low prealbumin levels, which reached values even below the normal range in some cases. Because excess intake of food is the reason behind many cases of obesity, individuals with high BMI are generally not recognized as malnourished. However, numerous studies demonstrated the opposite. Morbidly obese individuals have been shown to have mineral (e.g., selenium, zinc, iron) and vitamin (e.g., $B_{1}, B_{12}$, D) deficits [61]. Recent studies assessing the nutritional status of obese patients prior to bariatric surgery revealed that, despite an excess of calories, the intake of micronutrients was inadequate, leading to micronutrient deficiencies [62-64]. Therefore, due to the high prevalence of excess body weight in individuals with VLUs, nutritional supplementation appears to be particularly crucial to ensure optimal conditions for the wound healing process.

An individualized selection of adequate wound dressings according to the phase of healing can markedly 
Table 4. Serum prealbumin levels $(\mathrm{mg} / \mathrm{dl})$ during a 12-week supplementation with Cubitan formula $\left(n=35^{\dagger}\right)$

\begin{tabular}{lcccccc}
\hline Week & Mean & SD & $95 \% \mathrm{Cl}$ & Median & Range & $P_{\text {-value* }}$ \\
\hline W0 & 19.9 & 5.6 & $17.9-21.8$ & 19.0 & $11.0-33.0$ & 0.38 \\
\cline { 1 - 5 } W6 & 21.6 & 5.0 & $19.8-23.3$ & 21.0 & $12.0-36.0$ & \\
\cline { 1 - 5 } W12 & 21.9 & 5.2 & $20.1-23.7$ & 21.0 & $11.0-34.0$ & \\
\hline
\end{tabular}

${ }^{\dagger}$ One patient withdrew from the trial after W2. ${ }^{*}$ Calculated with ANOVA (Fisher test). SD - standard deviation, CI-confidence interval of the mean, WO - week $\mathrm{O}$ (baseline), W2 - week two; etc.

Table 5. Life quality assessment in WHOQOL-BREF questionnaire (Skevington, Lotfy, O'Connell, \& WHOQOL Group, 2004) for patients with venous leg ulcers supplemented with Cubitan formula $\left(n=35^{\dagger}\right)$

\begin{tabular}{|c|c|c|c|c|c|}
\hline \multirow{2}{*}{$\begin{array}{l}\text { WHOQOL-BREF scale } \\
\text { points }\end{array}$} & \multicolumn{2}{|c|}{ Initial assessment (W0) } & \multicolumn{2}{|c|}{ End of study assessment (W12) } & \multirow[t]{2}{*}{$P$-value* } \\
\hline & Median & Range & Median & Range & \\
\hline Physical & 22 & $17-29$ & 23 & $17-27$ & 0.796 \\
\hline Psychological & 20 & $14-25$ & 20 & $15-26$ & 0.0792 \\
\hline Social & 11 & $8-15$ & 11 & $8-15$ & 0.3942 \\
\hline Environment & 27 & $19-40$ & 29 & $19-40$ & 0.0003 \\
\hline General & 80 & $62-107$ & 83 & $65-104$ & 0.0013 \\
\hline
\end{tabular}

${ }^{\dagger}$ One patient withdrew from the trial after week 2 assessment. *Calculated with Mann-Whitney $U$ test. P-values $<0.05$ are marked in bold. WO - week 0 ; W12-week 12; etc.

improve the healing process. Here, we used advanced moisture-retentive AQUACEL ${ }^{\oplus}$ Foam dressings for effective exudate management, $\mathrm{AQUACEL}^{\oplus} \mathrm{Ag}$ Foam for infection and inflammation control, and, in the later phases of healing, hydrocolloid dressings- Granuflex ${ }^{\oplus}$ or Granuflex ${ }^{\oplus}$ Extra Thin to support sensitive newly produced tissues. AQUACEL ${ }^{\oplus}$ Foam dressings are characterized not only by their excellent absorbent and exudate handling capacities, but also for the comfort they provide to patients in terms of painless application and removal [65]. Foam dressings were also shown to reduce the activity of matrix metalloproteinases, MMP-2 and MMP-9 [66]. Such modulation may exert an additional favourable effect on the healing process as increased levels of metalloproteinases lead to excessive tissue degradation and can contribute to delayed wound healing [67].

In our study, adherence to the recommended ONS was satisfactory, demonstrating that the formula was well accepted by the patients. The rate of patient compliance to scheduled ONS intake reached $90 \%$, which is similar to the $84.8 \%$ reached in a corresponding study focused on pressure ulcers [18]. Similar percentages were described in a systematic review by Hubbard et al., where compliance with ONS was $78 \%$ overall and $81 \%$ for individuals in community settings specifically [68].

This study has certain limitations. The results are promising but still preliminary as no placebo group was included in the analysis. Additionally, the study group was heterogeneous in terms of patient body weight. It included patients with normal BMI but also overweight and obese individuals, who are at a high risk of chronic venous insufficiency and VLU.

\section{Conclusions}

We provided evidence that a complex management of VLU in a specialized centre including the application of advanced dressings and an energy-dense high-protein ONS enriched with amino acids, vitamins, and minerals, might benefit the healing process. The high acceptance levels of the ONS among older individuals indicate that it can serve as an easy-to-consume source of nutrients, allowing the patients to reach the nutritional status optimal for the wound healing. Such status is especially difficult to achieve with a standard diet in elderly patients, who often experience a decrease in appetite.

\section{Conflict of interest}

The authors declare no conflict of interest.

\section{References}

1. Stechmiller JK. Understanding the role of nutrition and wound healing. Nutr Clin Pract 2010; 25: 61-8.

2. Quain AM, Khardori NM. Nutrition in wound care management: a comprehensive overview. Wounds 2015; 27: 327-35.

3. Menke NB, Ward KR, Witten TM, et al. Impaired wound healing. Clin Dermatol 2007; 25: 19-25.

4. Dorner B, Posthauer ME, Thomas D; National Pressure UIcer Advisory Panel. The role of nutrition in pressure ulcer prevention and treatment: National Pressure Ulcer Advisory Panel white paper. Adv Skin Wound Care 2009; 22: 212-21.

5. Thompson C, Fuhrman MP. Nutrients and wound healing: still searching for the magic bullet. Nutr Clin Pract 2005; 20: 331-47.

6. Russell L. The importance of patients' nutritional status in wound healing. Br J Nurs 2001; 10: S42, S44-49. 
7. Todorovic V. Food and wounds: nutritional factors in wound formation and healing. Br J Community Nurs 2002; 7: S2, 43-54.

8. Jawień A, Szewczyk MT, Kędziora-Kornatowska K, et al. Functional and biopsychosocial restrictions among patients with a venous ulcer. Arch Med Sci 2006; 2: 36-41.

9. Szewczyk MT, Jawień A, Kędziora-Kornatowska K, et al. The nutritional status of older adults with and without venous ulcers: a comparative, descriptive study. Ostomy Wound Manage 2008; 54: 34-42.

10. Franks PJ, Barker J, Collier M, et al. Management of patients with venous leg ulcers: challenges and current best practice. J Wound Care 2016; 25: S1-67.

11. Debats IB, Wolfs TG, Gotoh T, et al. Role of arginine in superficial wound healing in man. Nitric Oxide 2009; 21: 175-83.

12. Kirk SJ, Hurson M, Regan MC, et al. Arginine stimulates wound healing and immune function in elderly human beings. Surgery 1993; 114: 155-9.

13. Levenson SM, Gruber CA, Rettura G, et al. Supplemental vitamin A prevents the acute radiation-induced defect in wound healing. Ann Surg 1984; 200: 494-512.

14. Molnar JA, Underdown MJ, Clark WA. Nutrition and chronic wounds. Adv Wound Care 2014; 3: 663-81.

15. Raffoul W, Far MS, Cayeux MC, Berger MM. Nutritional status and food intake in nine patients with chronic low-limb ulcers and pressure ulcers: importance of oral supplements. Nutrition 2006; 22: 82-8

16. Jawien A, Szewczyk MT, Kaszuba A, et al. Guidelines for the management of chronic venous leg ulceration. Recommendations of a multidisciplinary expert group. Leczenie Ran 2011; 8: 59-80.

17. O'Donnell TF Jr, Passman MA, Marston WA, et al. Management of venous leg ulcers: clinical practice guidelines of the Society for Vascular Surgery ${ }^{\oplus}$ and the American Venous Forum. J Vasc Surg 2014; 60: 3S-59S.

18. Cereda E, Klersy C, Serioli M; et al. Oligo Element Sore Trial Study Group. A nutritional formula enriched with arginine, zinc, and antioxidants for the healing of pressure ulcers. Ann Intern Med 2015; 162: 167-74.

19. Cereda E, Gini A, Pedrolli C, Vanotti A. Disease-specific, versus standard, nutritional support for the treatment of pressure ulcers in institutionalized older adults: a randomized controlled trial. J Am Geriatr Soc 2009; 57: 1395-402.

20. van Anholt RD, Sobotka L, Meijer EP, et al. Specific nutritional support accelerates pressure ulcer healing and reduces wound care intensity in non-malnourished patients. Nutrition 2010; 26: 867-72.

21. Nelzén O, Bergqvist D, Lindhagen A. The prevalence of chronic lower-limb ulceration has been underestimated: results of a validated population questionnaire. $\mathrm{Br}$ I Surg 1996; 83: 255-8

22. Jawień A, Grzela T, Ochwat A. Prevalence of chronic venous insufficiency in men and women in Poland: multicentre cross-sectional study in 40,095 patients. Phlebol J Venous Dis 2003; 18: 110-22.

23. Butcher M. Managing mixed aetiology leg ulcers. Pract Nurse 2002; 13: 161-6.

24. Simon DA, Dix FP, McCollum CN. Management of venous leg ulcers. BMJ 2004; 328: 1358-62.

25. Mościcka P, Szewczyk M, Cwajda-Białasik J, Jawień A. The role of compression therapy in the treatment of venous leg ulcers. Adv Clin Exp Med 2019; 28: 847-52.
26. Cwajda-Białasik J, Szewczyk MT, Mościcka P, Cierzniakowska K. The locus of pain control in patients with lower limb ulcerations. J Clin Nurs 2012; 21: 3346-51.

27. Szewczyk MT, Jawień A, Cwajda-Białasik J, et al. Randomized study assessing the influence of supervised exercises on ankle joint mobility in patients with venous leg ulcerations. Arch Med Sci 2010; 6: 956-63.

28. Gardner S. How to guide: Managing high exudate wounds. Wound Essentials 7. 2012. https://www.wounds-uk.com/ download/resource/1337. Accessed February 2, 2019.

29. Kondrup J, Allison SP, Elia M, et al.; Educational and Clinical Practice Committee, European Society of Parenteral and Enteral Nutrition (ESPEN). ESPEN guidelines for nutrition screening 2002. Clin Nutr 2003; 22: 415-21.

30. Falanga, V. Classifications for wound bed preparation and stimulation of chronic wounds: editorial. Wound Repair Regeneration 2000; 8: 347-52.

31. Eklöf B, Rutherford RB, Bergan JJ, et al. Revision of the CEAP classification for chronic venous disorders: consensus statement. J Vasc Surg 2004; 40: 1248-52.

32. Skevington SM, Lotfy M, O'Connell KA; WHOQOL Group The World Health Organization's WHOQOL-BREF quality of life assessment: psychometric properties and results of the international field trial. A Report from the WHOQOL Group. Qual Life Res 2004; 13: 299-310.

33. Callam MJ, Ruckley CV, Harper DR, Dale JJ. Chronic ulceration of the leg: extent of the problem and provision of care. Br Med J 1985; 290: 1855-6.

34. Olin JW, Beusterien KM, Childs MB, et al. Medical costs of treating venous stasis ulcers: evidence from a retrospective cohort study. Vasc Med 1999; 4: 1-7.

35. Ruckley CV. Socioeconomic impact of chronic venous insufficiency and leg ulcers. Angiology 1997; 48: 67-9.

36. Posnett J, Franks PJ. The burden of chronic wounds in the UK. Nurs Times 2008; 104: 44-5.

37. Agale SV. Chronic leg ulcers: epidemiology, aetiopathogenesis, and management. Ulcers 2013; 2013: 413604.

38. Berlowitz DR, Brienza DM. Are all pressure ulcers the result of deep tissue injury? A review of the literature. Ostomy Wound Management 2007; 53: 34-38.

39. Barwell JR, Davies CE, Deacon J, et al. Comparison of surgery and compression with compression alone in chronic venous ulceration (ESCHAR study): randomised controlled trial. Lancet 2004; 363: 1854-9.

40. Krasner D. Painful venous ulcers: themes and stories about their impact on quality of life. Ostomy Wound Management 1998; 44: 38-49.

41. Wellborn J, Moceri JT. The lived experiences of persons with chronic venous insufficiency and lower extremity ulcers. J Wound Ostomy Cont Nurs 2014; 41: 122-6.

42. Brownie $S$. Why are elderly individuals at risk of nutritional deficiency? Int I Nurs Pract 2006; 12: 110-8.

43. Martín Palmero Á, Serrano Pérez A, Chinchetru Ranedo MJ, et al. Malnutrition in hospitalized patients: results from La Rioja. Nutr Hosp 2017; 34: 402-6.

44. Rojas Al, Phillips TJ. Patients with chronic leg ulcers show diminished levels of vitamins A and E, carotenes, and zinc. Dermatol Surg 1999; 25: 601-4.

45. Wipke-Tevis DD, Stotts NA. Nutrition, tissue oxygenation, and healing of venous leg ulcers. J Vasc Nurs 1998; 16: 48-56.

46. Legendre C, Debure C, Meaume S, et al. Impact of protein deficiency on venous ulcer healing. I Vasc Surg 2008; 48: 688-93. 
47. Wild T, Rahbarnia A, Kellner M, et al. Basics in nutrition and wound healing. Nutrition 2010; 26: 862-6.

48. Parker CN, Finlayson KJ, Shuter P, Edwards HE. Risk factors for delayed healing in venous leg ulcers: a review of the literature. Int J Clin Pract 2015; 69: 967-77.

49. Szewczyk MT, Jawień A, Migdalski A, et al. Predicting time to healing by anatomical assessment of venous pathology. Med Sci Monit 2009; 15: CR74-81.

50. Hjerppe A, Saarinen JP, Venermo MA, et al. Prolonged healing of venous leg ulcers: the role of venous reflux, ulcer characteristics and mobility. J Wound Care 2010; 19: 474-84.

51. Barber GA, Weller CD, Gibson SJ. Effects and associations of nutrition in patients with venous leg ulcers: a systematic review. J Adv Nurs 2018; 74: 774-87.

52. Burkiewicz CJ, Guadagnin FA, Skare TL, et al. Vitamin D and skin repair: a prospective, double-blind and placebo controlled study in the healing of leg ulcers. Rev Col Bras Cir 2012; 39: 401-7.

53. de Franciscis S, De Sarro G, Longo P, et al. Hyperhomocys teinaemia and chronic venous ulcers. Int Wound J 2015; 12: 22-6.

54. Serra R, Grande R, Butrico L, et al. Effects of a new nutraceutical substance on clinical and molecular parameters in patients with chronic venous ulceration. Int Wound I 2016; 13: 8-96.

55. Wissing UE, Ek AC, Wengström Y, et al. Can individualised nutritional support improve healing in therapy-resistant leg ulcers? J Wound Care 2002; 11: 15-20.

56. Desneves KJ, Todorovic BE, Cassar A, Crowe TC. Treatment with supplementary arginine, vitamin $C$ and zinc in patients with pressure ulcers: a randomised controlled trial. Clin Nutr 2005; 24: 979-87.

57. Ellinger S, Stehle P. Efficacy of vitamin supplementation in situations with wound healing disorders: results from clinical intervention studies. Curr Opin Clin Nutr Metab Care 2009; 12: 588-95.

58. Schols JM, Heyman H, Meijer EP. Nutritional support in the treatment and prevention of pressure ulcers: an overview of studies with an arginine enriched Oral Nutritional Supplement. J Tissue Viability 2009; 18: 72-9.

59. Danielsson G, Eklof B, Grandinetti A, Kistner LR. The influence of obesity on chronic venous disease. Vasc Endovasc Surg 2002; 36: 271-6.

60. Davies HO, Popplewell M, Singhal R, et al. Obesity and lower limb venous disease - the epidemic of phlebesity. Phlebol J Venous Dis 2017; 32: 227-33.

61. Kaidar-Person O, Person B, Szomstein S, Rosenthal RJ. Nutritional deficiencies in morbidly obese patients: a new form of malnutrition? Obes Surg 2008; 18: 1028-34.

62. Roust LR, DiBaise JK. Nutrient deficiencies prior to bariatric surgery. Curr Opin Clin Nutr Metab Care 2016; 20: 138-44.

63. Wolf $E$, Utech $M$, Stehle $P$, et al. Preoperative micronutrient status in morbidly obese patients before undergoing bariatric surgery: results of a cross-sectional study. Surg Obes Relat Dis 2015; 11: 1157-63.

64. Lespessailles E, Toumi H. Vitamin D alteration associated with obesity and bariatric surgery. Exp Biol Med 2017; 242: 1086-94.

65. Tickle J. Positive clinical and patient outcomes with a nextgeneration foam dressing. Wounds 2016; 12: 56-62.

66. Krejner A, Grzela T. Modulation of matrix metalloproteinases MMP-2 and MMP-9 activity by hydrofiber-foam hybrid dressing - relevant support in the treatment of chronic wounds. Cent Eur J Immunol 2015; 3: 391-4.
67. Schultz GS, Sibbald RG, Falanga V, et al. Wound bed preparation: a systematic approach to wound management. Wound Repair Regen 2003; 11 Suppl 1: S1-28.

68. Hubbard, GP, Elia M, Holdoway A, Stratton RJ. A systematic review of compliance to oral nutritional supplements. Clin Nutr 2012; 31: 293-312. 